Viso - Cadernos de estética aplicada Revista eletrônica de estética

ISSN 1981-4062

$N^{\circ} 14$, jul-dez/2013

http://www.revistaviso.com.br/

\title{
Tudo podia ter sido diferente, tudo poderia ser diferente, tudo pode ser diferente
}

Irina Sandomirskaja 


\section{SANDOMIRSKAJA, I. "Tudo poderia ter sido diferente, tudo poderia ser diferente, tudo pode ser diferente". In: Viso: Cadernos de estética aplicada, v. VII, n. 14 (jul- dez/2013), pp. 56-63.}

DOI: $10.22409 / 1981-4062 / v 14 i / 165$

Aprovado: 18.02.2014. Publicado: 15.07.2014.

(C) 2014 Irina Sandomirskaja. Esse documento é distribuído nos termos da licença Creative Commons Atribuição-NãoComercial 4.0 Internacional (CC-BY-NC), que permite, exceto para fins comerciais, copiar e redistribuir o material em qualquer formato ou meio, bem como remixá-lo, transformá-lo ou criar a partir dele, desde que seja dado o devido crédito e indicada a licença sob a qual ele foi originalmente publicado.

Licença: http://creativecommons.org/licenses/by-nc/4.0/deed.pt_BR

Accepted: 18.02.2014. Published: 15.07.2014.

(C) 2014 Irina Sandomirskaja. This document is distributed under the terms of a Creative Commons Attribution-NonCommercial 4.0 International license (CC-BY-NC) which allows, except for commercial purposes, to copy and redistribute the material in any medium or format and to remix, transform, and build upon the material, provided the original work is properly cited and states its license.

License: http://creativecommons.org/licenses/by-nc/4.0/ 
Com os novos movimentos sociais surgidos nos últimos anos, de Nova lorque a Moscou e Istambul, da Índia ao Egito, a questão sobre as relações entre o politico e o carnavalesco tornaram-se novamente atuais, só que de maneira diversa. Na década de 2010, os movimentos carnavalescos de "Reclamação" e "Ocupação", como por exemplo Pussy Riot, constituem uma forte revolta contra o establishment e sua política neoliberal, inexistente tanto na época em que Bakhtin escreveu sobre o carnaval quanto na década de 1960, quando os seus textos começaram a ser lidos. Foi portanto num contexto político e cultural distinto que a relação entre prazer e violência e entre violência física e simbólica passou a nos "reclamar" e "ocupar".

Em seu modo de escrever a história da literatura, Bakhtin nunca se limita a uma pura factografia. Seus conceitos analíticos criam uma visão original da história ao mesmo tempo em que fazem alusões às circunstâncias políticas pertencentes ao seu próprio tempo. $\mathrm{Na}$ interpretação do leitor, esse alegorismo cria uma multivocidade ou, para usar um termo de Marcia Sá Cavalcante Schuback, uma inter-vocidade [Zwischendeutigkeit] que ele mesmo postulava em relação aos seus objetos teóricos. Conceitos como grotesco, diálogo e carnaval comportam sempre um duplo fundo e parecem referir-se a um nível invisível de sentido entre as linhas ou sob a superfície: uma espécie de revolução alegorizada, um lençol d'água radicalmente político, um excesso de sentido por detrás da máscara. Como um outsider no establishment científico soviético e um autor constantemente controlado pela censura, Bakhtin era uma figura misteriosa, com uma historia igualmente misteriosa e, mesmo após a sua morte, aparece na arena acadêmica como um bufão mascarado na praça do mercado.

Intervocidade também vale para as célebres palavras de Bakhtin, pronunciadas quase como slogan: Vsjo moglo byt' drugim. Dependendo de como se traduz o verbo modal moglo, essa frase pode dizer "tudo poderia ser diferente" ou "tudo pode ser diferente". Isso vale não apenas para o seu credo como historiador da literatura em revolta contra dogmas mas também para o leitor que não deve se deixar desviar nem pelo valor nominal da palavra e nem pela sua força normalizadora. Tudo pode ser diferente tanto agora como no futuro, no mesmo grau em que antes tudo também podia ter sido diferente. Surpreendentemente, a sua intervocidade pode ser tanto super-pessimista como uma afirmação de vida: uma duplicidade que constitui a quintessência do carnavalesco. A face de Bakhtin sempre se esconde atrás de uma ou outra máscara; um corpus de texto está sempre sustentado numa grotesca transformação e um campo intelectual encontra-se sempre em contínua desterritorialização. Mediante contínuas interpretações, o pensamento de Bakhtin se aproxima de um diálogo ininterrupto consigo mesmo: uma força criadora que a cada nova leitura luta contra si mesma e aniquila o sentido por ela mesma já estabelecido, para depois estabelecer de um outro modo um novo sentido. Seu mundo de pensamento constrói-se através de um conflito irreconciliável consigo mesmo, tendo por base o antagonismo como seu fundo (sem) 
fundo. É muito estranho que um pensador, capaz de exercer tamanha violência contra o próprio pensamento, contra a própria língua e contra o mundo sobre o qual reflete, tenha se tornado tão central e incontornável para o pensamento contemporâneo da nãoviolência, para a sua política e a sua estética, seus movimentos lúdicos de "Ocupação" e suas provocações aparentemente inocentes e não perigosas.

Os sobretons políticos que podem ser vislumbrados na teoria literária de Bakhtin surgem da meta-história inteiramente específica, por ele elaborada entre as linhas. Os três conceitos centrais do pensamento de Bakhtin - diálogo, carnaval e corpo grotesco formam uma trindade, três princípios inseparáveis e reciprocamente complementares dentro de uma e mesma fenomenologia do tempo. Importante é que todos os três possuem uma origem comum na violência.

O diálogo representa uma força violentamente destruidora-criadora dentro da linguagem, uma unanimidade infinita e ao mesmo tempo uma irreconciliável desunião, uma coexistência de sentido num conflito contínuo entre o que Bakhtin chamou de "forças centrípetas e centrífugas da linguagem". Destruindo e esvaziando velhos sentidos estabelecidos, essa cooperação na resistência cria ininterruptamente mais do que novas formas de linguagem.

Tão violento como o diálogo é o carnaval com sua alegria infernal desafiando tudo o que é levado a sério, revirando todas as hierarquias, aniquilando todas as formas, de maneira a reunir, após arrebentar relações sociais, corpos individuais numa co-pertença sem forma: o corpo coletivo do povo sem limites ou diferenças interiores. Dentro da totalidade antiestética do carnaval, não se faz diferença entre risos e lágrimas, entre alimento e excremento, entre tudo e nada, entre eu e nós. Como acontecimento social, o carnaval produz ainda o seu próprio sujeito, inteiramente peculiar: o corpo grotesco sem nenhum organismo ou sistema identificável. Este de fato não possui nenhum corpo ou membro a não ser uma boca tão grande e aberta como o ânus. Em sua alegria ilimitada, esse corpo é capaz de comer - e depois também facilmente digerir e expelir - todo o cosmo, de maneira que até mesmo o todo do mundo possa por sua vez ser engolido, aniquilado e liberado.

Essa é a economia política na realidade carnavalesca do diálogo: uma circulação infinita de vida impossível de se distinguir da morte, uma troca de sentido que só de maneira absurda faz sentido. Essa é também a meta-história da modernidade, segundo Bakhtin. Um metabolismo sem limite e incessante, que consiste de vida, morte, matéria, linguagem e tempo; um tempo místico que não se desenvolve linearmente mas em séries de repetição, num movimento contínuo de renascimento e extermínio, autocriação e autodestruição. É uma tal narrativa meta-histórica que, segundo Bakhtin, reúne a linguagem, o agir politico e o corpo num drama triangular - ou talvez numa tragédia triangular - tendo como cerne uma violência desumana, sobre- humana. 
Essa fantasmagoria encobre um modelo teórico para apreender uma história totalitária e uma economia política do terror. Isso torna ainda mais estranho que os atuais movimentos politico-culturais pós-totalitários, não violentos se vejam engajados em Bakhtin. Isso talvez mostre algo importante, mesmo que não explícito, a saber, o fato de que, na democracia liberal de hoje, é possível reconhecer-se na descrição de fundo duplo da Rússia totalitária de Stalin.

Apesar de sua visão única da história e do hoje, Bakhtin não era o único entre os intelectuais do tempo de Stalin a produzir uma pesquisa orientada por uma meta-história alegórica. Outros também buscaram modos de pensar histórica e teoricamente sobre a modernidade soviética, as suas catástrofes políticas e o seu sofrimento humano. $\mathrm{O}$ pensamento oficial da história de Stalin baseava-se numa fé estritamente sóciodarwinista no curso linear da história, tendo o comunismo como estação final. Esse era o mito dominante na prática, apesar da confessada dialética: para representar um futuro luminoso, uma linha reta funcionava melhor do que a complicada espiral hegeliana. Formalistas russos tentaram formalizar a história ao lançarem uma teoria sobre uma temporalidade circular construída por repetições de circunstâncias sociais e políticas semelhantes através dos tempos. Só se pode conceber sentido no agora, mediante uma comparação estrutural com um episódio histórico anterior. Em outras palavras: para se compreender a sociedade soviética após a revolução fazia-se um paralelo com o tempo após a Guerra napoleônica, com a insurreição dos decabristas e com o particular peso simbólico dessa época. A renascença artística da Rússia no século $X X$, principalmente a vanguarda (que tanto estética como politicamente estava mais próxima dos formalistas) era comparada ou bem com o final do século XVIII, quando surge a literatura moderna russa, ou então com a revolução poética de Puchkin, entre 1820 e 1830. Os formalistas consideravam que o terror de Stalin e o surgimento do realismo socialista eram estruturalmente semelhantes às fortes reações políticas durante o governo de Nicolau I.

Essa temporalidade circular lembra não só a espiral dialética de Hegel e Marx mas, sobretudo, o eterno retorno do mesmo em Nietzsche. O retorno cria a história como uma totalidade e confere ao tempo a sua estrutura: o agora histórico rima com o passado mais ou menos como rimam num poema diferentes palavras que assim se estruturam como um poema. Da mesma maneira que a revolução na linguagem poética provém da periferia da linguagem, também a revolução política provém de confins histórico-políticos. Ela perturba o centro dogmático do sistema para depois assumir e renovar todo o sistema. Não obstante, com o decorrer do tempo, tudo que alguma vez foi novo torna-se velho e reacionário. Uma revolução poética (política) se transforma num novo dogmatismo e a renovação revolucionária sucumbe em rotinas poéticas (burocráticas) até que por fim uma nova periferia se torne suficientemente forte para realizar uma nova revolta. Assim como Bakhtin, os formalistas encontravam-se sob a forte influência da censura abrangente e por isso nunca conseguiram tempo para formular com clareza suas ideias, tendo que incentivar os seus leitores a interpretarem as entrelinhas. Quando, por exemplo, tornou-se impossível para o formalista Jurij Tynjanov dar 
continuidade à sua atividade de teórico da literatura, ele começou a escrever estórias e romances históricos. Isso não foi apenas um modo de evitar a censura e conseguir formular seu pensamento histórico-critico sob a forma de uma narrativa ficcional. A geração entre 1920 e 1930 podia de fato se reconhecer na sua descrição da situação artística e política do império russo cem anos antes. Os romances históricos de Tynjanov tornaram-se, para os intelectuais soviéticos, um conto da vida coletiva, uma história alegórica sobre a vanguarda e o seu desparecimento durante a normalização de Stalin. Tynjanov criou a sua narrativa entre as linhas a fim de postular o "eterno retorno" do império como a lei imanente da história russa. Já Bakhtin criou alegorias históricoliterárias que politizaram tanto o passado como o agora.

Para compreender as implicações políticas e esclarecer as curiosas sintonias entre a voz polifônica de Bakhtin e os protestos plurivocais de hoje não se deve atentar apenas para esse contexto russo; há também uma moldura teórica europeia. Um tal contexto dialógico encontra-se também em um outro teórico muito importante - Walter Benjamin particularmente no que concerne à questão da violência. Violência é um tema tão central não só no pensamento de Benjamin e no de Bakhtin mas também no ativismo atual, caracterizado por uma violência simbólica enquanto instrumento contra o abuso econômico e político do sistema neoliberal.

Benjamin escreveu "Para uma crítica da violência" no começo de 1920 no intuito de refletir teoricamente sobre a decisiva diferença entre dois tipos de violência. Simplificando um pouco: trata-se da diferença entre uma violência enquanto renovação da história e força criadora tal como exercidas na revolução e uma outra violência que é a brutalidade do estado policial com vistas a preservar a ordem vigente.

Distintamente de tentativas anteriores preocupadas em legitimar eticamente a violência da revolução ou, ao contrário, em negar toda violência enquanto crime contra a sacralidade da vida, o materialista histórico Benjamin propõe uma explicação metahistórica ou, como os céticos costumam dizer, mística ou messiânica. Essa explicação encontra-se tremendamente próxima da apreensão bakhtiniana da violência simbólica no carnaval e no diálogo. A teoria da violência desenvolvida por Benjamin foi discutida e questionada pelos filósofos mais influentes do nosso tempo como Derrida, Agamben e Zizek. Como foi dito, Benjamin postula dois tipos de violência como forças propulsoras da história. A origem da revolução encontra-se na violência divina ou pura. É precisamente essa violência "pura" que excede todas as condições políticas e assim legitima a revolução. A violência "pura" pertence ao tempo como tal, uma energia destrutiva que sustenta o mundo. É "divina" por manifestar a força imanente da criação de Deus, uma energia messiânica que, apesar de todas as limitações políticas e históricas, promove a criação. 
É de admirar que se possam encontrar paralelos tão visíveis entre as esclarecedoras discussões de Benjamin sobre a violência divina e a maneira de Bakhtin construir o carnaval. Ambos descobrem aqui uma força supra-histórica em busca de uma pura transformação e nada mais; uma transformação pela transformação, sem nenhuma finalidade prática ou qualquer teleologia política ou teológica. A violência pura em Benjamin, assim como o carnaval em Bakhtin, são categorias para se conceber a capacidade infinita da negatividade, que pode tanto aniquilar como gerar uma energia meta-histórica que determina, na política e na história, uma espécie de revolução permanente dentro da criação do mundo, o desenvolvimento abrangente do todo num movimento sem fim ou finalidade. São os princípios violentos na economia da criação do mundo que formam e levam adiante o tempo.

Existe portanto uma certa afinidade entre Bakhtin e Benjamin, nas suas concepções semelhantes da origem mística da história. Isso se deve em parte ao fato de ambos terem buscado uma explicação para a história da modernidade através de uma reflexão filosófica sobre as narrativas bíblicas, criando assim paradigmas estruturais. Benjamin exemplifica a sua teoria da violência com um episódio do quarto livro mosaico enquanto Bakhtin encontra nos diálogos do livro de Jó o protótipo do diálogo.

A violência mística nesses dois pensadores - a violência divina em Benjamin e o diálogo bíblico em Bakhtin - encontram seus antípodas na violência do poder político: a brutalidade da "preservação do direito" do poder, a violência do estado contra cidadãos em protesto ou a violência da polícia contra os revolucionários. Esse tipo de violência busca tanto preservar o status quo como também impedir o desenvolvimento puro ou divino do tempo (da criação). Todavia, tanto em Benjamin como em Bakhtin, a violência "impura" da normalização possui uma extensão cultural-política mais ampla e vale não apenas como repressão política contra a revolução. Em Bakhtin, o poder politico (e ilegítimo) reside na forma. A forma é uma delimitação estética e politicamente forçada que impede o livre desenvolvimento da língua através de normalização. Para Benjamin, a violência "não-divina", "impura" reside na representação como tal. Cada ato de designação ou representação é ao mesmo tempo uma ação do poder politico com vistas a preservar a autoridade, a cimentar as fronteiras e a glorificar os detentores do poder. $\mathrm{O}$ exemplo de Benjamin é a vingança de Apolo contra Níobe: ele pune Níobe matando seus filhos e deixando-a em vida. Além de torturá-la com o sofrimento eterno, ele também revela no seu corpo tornado pedra uma eterna lembrança da sua ira, um monumento inumano da arbitrariedade.

Aqui reencontra-se um importante elemento político no ativismo social, político e artístico de hoje na forma de "reclamação", "ocupação" ou "provocação". Trata-se da questão da legitimidade da violência e, sobretudo, da violência simbólica. Quem tem direito a isso em nosso tempo de comunicação altamente tecnológica e da omnipresença da propaganda? Uma pergunta semelhante pode ser formulada com ajuda da diferença proposta por Bakhtin entre a violência legítima do carnaval e a violência "séria", mas 
ilegítima, da normalização. A norma expropria o divino e o utiliza para as suas finalidades políticas. O carnaval desafia as normas e deixa uma parte do poder simbólico para o povo.

Um exemplo de expropriação pode ser encontrado na campanha de propaganda para cruzeiros de carnaval ou em como o Microsoft Word me manipula agora enquanto escrevo esse texto ao me conduzir por um labirinto de caixas de diálogo. Tanto o carnaval como o diálogo são aqui apenas nomes para realidades simuladas, criadas com a intenção de produzir lucro ou de impor uma rotina administrativa. A linguagem de Bakhtin foi expropriada para designar uma falsa satisfação com pseudo-valores comercial e burocraticamente construídos como o prazer, o conforto e a ordem. A tarefa política hoje consiste em recarregar o sentido das palavras carnaval e diálogo em Bakhtin.

Os ativistas de hoje encenam provocações artísticas para pro-vocar (do latim pro = para frente, vocar $=$ dizer), ou seja, fazer vir à palavra uma sociedade que esconde suas intenções seja por medo ou então por vender seus princípios em troca de conforto econômico. É uma luta não-violenta contra a violência simbólica do sistema em meio a um cronotopo multi-dimensional, criado pela trindade bakhtiniana: diálogo, carnaval e corpo grotesco. Nesse cronotopo, ecoa com força o slogan bakhtiniano, que passa a soar como promessa: tudo podia ter sido diferente, tudo poderia ser diferente e tudo pode ser diferente.

\footnotetext{
* Irina Sandomirskaja é professora titular de Cultural Studies na Södertörns University College/Suécia.
} 